\title{
'A male dominance kind of vibe': Approaching unsolicited dick pics as sexism
}

new media \& society 202I, Vol. 23(6) I465-1480 (C) The Author(s) 2021

Article reuse guidelines: sagepub.com/journals-permissions DOI: | 0.1 I 77/| 46 | 444820907025 journals.sagepub.com/home/nms

(\$SAGE

\section{Rikke Amundsen}

University of Cambridge, UK

\begin{abstract}
This article explores women's accounts of receiving unsolicited dick pics from men. Drawing on material derived from in-depth interviews with adult British women, its focus is on how these interviewees relied on a postfeminist discursive framework in order to make sense of such experiences, and on how this rendered them more likely to recognise unsolicited dick pic practices as acts of sexism. As such, these women also felt encouraged to respond to their receiving of unsolicited dick pics by engaging in humorous practices of anti-sexist resistance. Still, the article also shows how the interviewees' drawing on a postfeminist discursive framework rendered them more prone to approach unsolicited dick pic practices and sexism in individualised and decontextualised manners, meaning that they failed to recognise and critically address the broader social structures that enable dick pics to circulate online as acts of sexism in the first place.
\end{abstract}

\section{Keywords}

Dick pics, individualism, postfeminism, sexism, sexting

\section{Introduction}

I think it's quite an aggressive gesture, not a particularly pleasant one. [. . .] they're more of a kind of controlling thing, like: 'you now have to look at my penis, whether you like it or not'.

- Yasmin (mid-20s)

In the autumn of 2016, Yasmin and I sat down for an interview on women's use of new media and digital technology in their romantic and/or sexual relations. Some time into the

\section{Corresponding author:}

Rikke Amundsen, Department of Sociology, University of Cambridge, 16 Mill Lane, Cambridge CB2 ISB, UK. Email: rba26@cam.ac.uk 
interview, I asked her to talk about the digitally mediated experience of receiving private sexual images. In posing this question, I did not refer to a particular kind of private sexual image or state whether I meant solicited or unsolicited sexual imagery. Nevertheless, as Yasmin set out to answer my question, she immediately turned to the topic of unsolicited dick pics (DPs). Like many of the other women also interviewed for the same project, she was of the assumption that, when I asked about women's receiving of private sexual images, what I really was asking about, was women's receiving of private sexual images that men create of their own genitals and send to women, without asking for their consent to do so. Arguably, this assumption was grounded in the expectation that I too was aware of the rising frequency of this unwanted activity (Smith, 2018). ${ }^{1}$ In casting men's unsolicited DP practices as an unpleasant act of aggression and as a male attempt at exerting some level of control over women, Yasmin's description of unsolicited DPs in heterosexual relations as a kind of violation is representative of my interviewees' general take on this phenomenon. As such, it is also representative of the focus of this article, which explores adult women's accounts of receiving unsolicited DPs from men.

So far, DPs in heterosexual relations remain a relatively unexplored socio-technical phenomenon (Hayes and Dragiewicz, 2018: 118). However, some excellent research does exist on this topic, and this research is largely theoretical or grounded in qualitative research, based either on discourse analysis or interviews (Mandau, 2020). In terms of focus, the literature based on this research can be divided into two distinct, yet intersecting, subsets. The first subset is primarily concerned with DPs as they occur in the context of youth culture. This literature tends to address DP practices as a variant of the activity of 'sexting' - here understood as the digitally mediated activity of creating, sending and receiving private sexual images (Burkett, 2015; Mandau, 2020; Ricciardelli and Adorjan, 2019; Ringrose and Harvey, 2015; Salter, 2016; Setty, 2018, 2020) The other subset of this literature is mainly concerned with unsolicited DPs, here explained as a technologically facilitated means through which men of no specified age group - intentionally or unintentionally - harass, intimidate or hurt women (Hayes and Dragiewicz, 2018; Ringrose and Lawrence, 2018; Thompson, 2016; Vitis and Gilmour, 2017). This second subset of the literature includes research that explores the experiences of women under the age of 18, meaning that, in the United Kingdom, they are legally defined as children. Indeed, the question of age is important in relation to any academic research on the topic of DPs, primarily because of the legal implications involved and the social concerns that are often raised when individuals legally defined as children create, share and receive private sexual imagery. ${ }^{2}$ In addition to these two main subsets of the existing DP literature, some research has also stressed the important point that consensual heterosexual DP practices - adult or otherwise - can work as a means to express intimacy and/or desire (Paasonen et al., 2019). At the moment of this article being written, only one piece of research has explored the phenomenon of DPs in heterosexual relations exclusively from adult men's perspective, and this research is grounded in a survey that examines men's motivations for sending unsolicited DPs to women (Oswald et al., 2019).

Situating itself at the intersection of the existing research examining DPs in the context of heterosexual relations, the key aim of this article is to provide an in-depth examination of adult women's accounts of their receiving of unsolicited DPs, a topic which, until now, remains unexplored through in-depth interviews with members of this age 
group. Another, more particular goal with this article, is to develop an understanding of the discursive processes through which these adult women come to understand unsolicited DPs as a form of sexism.

I commence this article by focusing on how the interviewees' accounts of women's receiving of unsolicited DPs were informed by their thinking through a postfeminist discursive framework promoting notions of free choice, individual agency and female empowerment (Gill, 2007). Moreover, I show how they operated with an understanding of 'consent' that was inherently associated with their rights to autonomy and to choose for themselves when, how and where to engage in sexual acts of communication, offline as well as online. Here, I also consider how their thinking through postfeminist frames enabled their understanding of these unwanted images as digitally mediated articulations of sexism. Next, I examine how this conception of unsolicited DPs operated as an incentive for the women to apply irony and wit as a means of altering the sexist meanings of the unsolicited DPs that they received. As such, I make a contribution to the growing field of academic literature concerned with women's use of humour in order to challenge and subvert articulations of sexism online (Ringrose and Lawrence, 2018). ${ }^{3}$ However, I also show how the interviewees' thinking through a postfeminist discursive framework underpinned by a 'grammar of individualism' led to their developing equally individualised and, relatedly, decontextualised understandings of unsolicited DPs as sexism (Gill, 2007: 153). Essentially, their reluctance to situate unsolicited DPs within the broader socio-technical context in which they originate and gain meaning, prevented their development of a fully informed grasp of the various structural elements that come together in making these acts possible, and that enable their operations as online sexism in the first place. Crucially, I argue that this approach to unsolicited DPs as sexism is characteristic of what Rosalind Gill and Laura Favaro (2018) has cast as a 'rebranded feminism': a form of feminism so focused on the individual that notions of gender equality become severely stripped down, and which contains few - if any - calls for collective action. In the concluding section of the article, I problematise the tendency of my interviewees to not take into full consideration the broader socio-technical context in which unsolicited DPs are created, circulate and gain their sexist meaning. In doing so, I argue that, if the overarching aim in calling out unsolicited DPs as acts of sexism is to hinder this activity form happening from the outset, this focus on the individuals that create and distribute these images is too narrow: we need to broaden our scope by situating this phenomenon within the socio-technical context in which it occurs. Doing so is useful, because it aids the development of an improved understanding of the predominant gendered conventions that operate in this context, and that feed off and into this particular socio-technical phenomenon and the meanings that it acquires.

Before I delve into an exploration of the interview material, I will provide an introduction to how these data were collected and to the analytical approach that guides my interpretation of it.

\section{Methodology and analytical framework}

This article examines interview material derived from an exploratory research project on women's use of new media and digital technology in their romantic and/or sexual 
relations with men, conducted with a specific focus on women's experiences of sexting. Overall, the aim of this study was to examine how the incorporation of new media and digital technologies into the intimate domain informs practices and perceptions of intimacy.

Between June 2016 and February 2017, I conducted 44 in-depth individual interviews with women aged 18-38 and based in Cambridgeshire, UK. These interviews were informed by an open interview guide, which was centred around questions regarding the interviewees' views on and experiences of the consensual and non-consensual creating, sharing and receiving of private sexual images. Being the sole interviewer, I considered it my main task to listen carefully to what these women told me, for so to pick up on the most relevant and/or interesting aspects of what they said, before asking follow-up questions. Unsolicited DPs were therefore not a topic that I intentionally brought up during our conversations. Rather, as illustrated by the example with Yasmin (mid-20s) in the article introduction, it was something that many of the interviewees turned to when asked about their experiences of receiving private sexual images in general. I, hence, operate with an understanding of this interview material as something that was "collaboratively generated' between the interviewee and myself and in and through our interaction (Roulston, 2010: 5). I recorded and transcribed all interviews, before I conducted a thematic analysis of these, using coding software Atlas.ti (Braun and Clarke, 2006). As this is an exploratory study - driven by my feminist convictions and interests in gender and mediated intimacy - my only requirement in recruiting was that participants should be self-defining women, aged 18 and over and based in Cambridgeshire, UK. After being granted ethical approval from my department's Ethics Committee, I reached out to and connected with these women through purposive network and snowball sampling, meaning that a key concern in my work to anonymise them was to avoid the possibility of deductive disclosure (Kaiser, 2009). Owing to this, all interviewees are assigned pseudonyms consisting of randomly allocated standard British names. Each participant signed an informed consent form and received a participant information sheet, in addition to a sheet with the contact details of organisations like the Revenge Porn Helpline, which could assist them should they have any sexting-related issues or concerns.

While 42 of the 44 women were either in the process of undertaking a higher education degree, or they had already taken 1 or more such degrees, the interviewees were otherwise of a broad range of social and/or cultural backgrounds and identity characteristics: 30 identified as heterosexual, 10 as bisexual, 1 as 'queer', 1 as lesbian and 2 as not sure of their sexualities. Thirty-five described themselves as White British or White Other, with four identifying as South Asian, two as East Asian, two as Mixed British/ African, and one as Mixed British/Asian. One of the women described herself as a 'stayat-home mother', while the remaining 43 were professionally employed and/or undertaking higher education degrees. Twenty-two were in relationships and 22 were single. Six of the women had one or more children. I did not ask if they had any disabilities, and none of them mentioned having one either. All of the women identified as 'woman' and I did not probe any further than that regarding their gender identities.

Despite operating with a perception of gender that is distinctly intersectional - I understand each individual expression of womanhood to be articulated according to where it is situated in relation to various '[axes] of differentiation' (Brah and Phoenix, 
2013: 76) - this article is going to analytically foreground the interviewees' notions of male and female gender as these are socially defined (Butler, 1990). With regard to how the interviewees discussed this topic, I did not recognise any differences across demographics. That being said, I acknowledge that my sample is mainly White and highly educated, something that might have informed the findings presented in this article. Here, I am particularly concerned with exploring the postfeminist discursive framework that the interviewees generally relied on in making sense of their experiences of receiving unsolicited DPs. More specifically, my main preoccupation is to examine how the 'grammar of individualism' that underpins this framework informed the interviewees' accounts of unsolicited DPs as sexism, thus leading to their development of essentially individualised and decontextualised understandings of both these phenomena (Gill, 2007: 153).

Postfeminism, as I use the term here, is a cultural sensibility in which feminism is simultaneously taken into account and undone through the 'double-entanglement' of feminist and anti-feminist ideas (Gill, 2007; McRobbie, 2004). Understood as such, postfeminism points to a 'cultural landscape' in which certain facets of feminism are incorporated into social and political life, thus making the social movements on which feminism is based appear to be 'a spent force' and, owing to this, as no longer necessary (McRobbie, 2004: 255-256, 2009: 12; O’Neill, 2018: 16). Following Gill (2007, 2017) I approach postfeminism as a sensibility marked by its close affiliation with neoliberalism, a form of governance that promotes individual entrepreneurialism, choice and responsibility as the ideals by which people - and especially young women - should lead their lives (Brown, 2003; Gill, 2007; O’Neill, 2018: 16; Rose, 1996). I also follow Gill (2007, 2017) in addressing postfeminism as a sensibility constituted by a range of reoccurring and often contradictory themes, including, precisely, a characteristically neoliberal 'focus upon individualism, choice and empowerment' (Gill, 2007: 149). In this article, I pay special attention to the ways that this postfeminist theme fed off and into my interviewees' accounts of unsolicited DPs as sexism, and how this led to their developing equally individualised perceptions of unsolicited DPs specifically, and of sexism generally. In doing so, my goal is to show how their drawing on a postfeminist discursive framework enabled their recognising unsolicited DPs as acts of sexism and, as such, motivated their engagement in certain acts of anti-sexist resistance while, at the very same time, it worked to obscure from view the unequal and highly gendered social structures that both grant unsolicited DPs their harmful meanings and make such sexist practices possible from the outset. In relying on this understanding of postfeminism, I also use this concept empirically (Banet-Weiser et al., 2019: 2), meaning that I think with this particular understanding of postfeminism in order to understand adult women's accounts of unsolicited DPs as sexism.

\section{'It's kind of invasive': making sense of unsolicited DPs}

When I asked my interviewees how they felt about receiving unsolicited DPs, most of them explained this experience by describing how such unwanted imagery worked so as to violate women's right to make free choices as well as their notions of power and control. Many of the women described unsolicited DP practices as expressions of men's 
superior level of control within the intimate domain, as illustrated by their ability to deprive women of theirs. For instance, during her early adolescence, Tia (late teens) had created a social media profile on which she pretended to be an adult woman so as to have conversations 'of a sexual nature' with adult men. Some of the men on this platform had sent 'photos of their genitals' to Tia's fake profile, without her asking for it. Tia described this event as 'uncomfortable and disturbing' sensations that she now made sense of by pointing out how this experience had made her feel out of control:

Um I just felt quite like, um, I guess almost violated by it. Because, I . . ah, it's like I had no, it just came into my inbox and [. . . I had no control over that happening. Um and I felt kind of shocked and like disgusted by it.

To Tia, the most difficult aspect of receiving these unsolicited images was the fact that the men who sent them effectively deprived her of her right to choose when or if she was to receive these images from the outset. As such, she felt like she lost control of these intimate and/or sexual interactions, and even over whether to be involved in them at all. This view that men's unsolicited DPs were disturbing because of their ability to deprive women of control was echoed in several of my interviews. For example, as seen in the quote that opens this article, Yasmin (mid-20s) described such images as 'more of a kind of controlling thing, like; "you now have to look at my penis whether you like it or not", thus rendering visible the similarities between her account of unsolicited DPs and accounts of flashing as it occurs offline. ${ }^{4}$ Certainly, the social and gender dynamics involved in the non-consensual distribution of DPs 'appear to mimic the dynamics of sexual harassment in other contexts' like flashing, wherein the non-consensual exposure of male genitals operates as means to cause offence and/or to express a sense of male sexual or aggrieved entitlement (Hayes and Dragiewicz, 2018: 115, 117).

Like Yasmin, most of the interviewees were not just upset about the reduced level of control over their intimate interactions that the men's sending of unsolicited DPs involved for them, but also about the perceived lack of ability to self-govern that their receiving of such imagery brought about. For instance, this view was reflected in my interview with Whitney (late 20s). After a first date with a man she had met on an online dating platform, Whitney decided that she did not wish to date this man again. In response to Whitney's rejection, the man sent her unsolicited DPs every other day for about a month:

I started to feel kind of quite, like it was quite violating of my like personal space and privacy. And I think maybe the technology wasn't as good at that point [maybe four years ago], I couldn't, well, it wasn't as easy for me to find out how to block them, or how to kind of put a stop on them myself. So I didn't feel like I had an awful lot of autonomy in terms of dealing with the invasion.

The man's ability to invade her privacy by sending DP after DP, without any concern for her wishes or desires, made Whitney feel deprived of her autonomy. As such, her view of this act was representative of that presented to me in the majority of the interviews, namely that men's sending of these kind of images were wrong, because they rendered women incapable of operating freely so as to govern their own selves by choosing whether or not to receive such imagery in the first place. 
Notions of female empowerment and the ability to exercise control were valued particularly highly by my interviewees. Their experiences of a lack of self-control, as brought about by the receiving of unsolicited DPs, could therefore feel especially painful. However, their very drawing on a postfeminist discourse, marked by a focus on individualism, free choice and female empowerment, was also that which enabled them to make sense of men's sending of unsolicited DPs as articulations of sexism in the first place. Indeed, this discourse prevented some of the women from simply taking such behaviour for granted as inevitable and thus all right. In the following account by Imogen (mid-20s), we can see how her drawing on this discursive framework helped her to develop an understanding of men's unsolicited DPs as violations of her individual rights:

I think partly it's like, if you don't know what's coming when you're opening a message and it's like a sexual image, it's kind of invasive. It's like; 'I don't wanna see this. I didn't choose to see this. I didn't consent to this', kind of thing. Like I don't think it's OK to send unsolicited like sexual anything, like sexual messages, sexual images to, especially to strangers, but kind of to anyone. I think it needs to be like a base level of consent established before you start sending that kind of things. And also I think it is, I think it is sexually aggressive. Like it's like 'look, I can get into your inbox, I can show you my penis, I can try and sexually entice you with this photo'. And it's just, yeah it's kind of like a male dominance kind of vibe.

Imogen made sense of her experience of receiving unsolicited DPs by thinking through concepts like free choice and power (here referred to as 'consent' and 'domination'). In doing so, Imogen also came to interpret unsolicited DPs as expressions and enhancements of men's superior level of control to women in the intimate domain. Crucially, Imogen's thinking through concepts like free choice and power to understand unsolicited DPs also encouraged her to see such images as acts operating to deprive women of their equal rights to make free choices within this domain ('It's like: "I don't wanna see this. I didn't choose to see this. I didn't consent to see this"'). The account above by Imogen is hence a good illustration of the ways that the interviewees held notions of individual control and free choice in such a high regard that acts that so evidently were conducted without consideration for these rights - even if conducted with the intention to 'sexually entice' the woman at the receiving end - were cast as negative and recognised as acts of male domination and expressions of sexism. This also shows how the women's drawing on a postfeminist discursive framework emphasising individualism, free choice and female empowerment did not only simply operate so as to highlight their perceptions of unsolicited DPs as a violation, but also to provide some of them with the necessary encouragement to set out to regain some level of individual control by engaging in humorous forms of anti-sexist resistance, following an unwanted sexual interaction involving unsolicited DPs.

\section{'Kind of like, commiseration': responding to unsolicited DPs}

While a significant number of the women who participated in this study cast their receiving of unsolicited DPs as part and parcel of the experience of being a woman online, thus framing it as something that they could do little about and as something that they just had 
to deal with online, others were more reluctant to accept this perceived inevitability of the situation..$^{5}$ Among this latter group of women, some aimed to challenge the men who engaged in such unwanted practices by pushing back against what they saw as a violation of their individual rights, primarily through the use of humour. For example, Stephanie (early 30s) sometimes responded to men's unsolicited DPs with irony, sending a 'critique' of the unsolicited DP back to the sender:

You get used to [receiving unsolicited DPs], cos you get it quite a lot. Um I tend to critique, I'd send a critique back. [. . .] So once, on [an online dating platform] this guy sent me actually a really well written and very nice message, accompanied by five or six pictures of himself. Um and he was like: 'I'm not interested in a relationship, but I'm really interested in having sex'. Basically; 'here's the goods' [laughs]. [. . . . Um but I wasn't even interested in that at the time, so I was saying that, I don't know; 'I'm OK thank you, I'm not offended and your message was nice and I'd rather people were upfront, but with the pictures of your penis, can I recommend that you' - I don't know - 'have your pants off rather than have it sticking outside of them as it looks a bit weird'. Um, and like, stuff like that [short laugh]: 'That's not quite how I'd present myself' [laughs].

While Stephanie cast women's receiving of unsolicited DPs on online dating platforms as common - thus describing it as something you get 'used to' and that she did not 'really get offended by' - she was also acting so as to challenge the men who sent such unwanted material by responding in ironic and unexpected ways. This use of humour as a means to respond to unsolicited DPs can hence be understood as a means to 'take back some agency' in a situation where one finds oneself at the receiving end of unwanted, interpersonal communication (Handyside and Ringrose, 2017: 358). Indeed, as we can see from Stephanie's account earlier, 'witty responses' can operate as a form of 'counter-discipline', whereby the woman who receives the unsolicited DP responds to it in challenging ways, thus troubling the unequal power dimensions that such acts of unsolicited communication intend to establish (Calder-Dawe, 2015: 96-97; Hess and Flores, 2018: 1085).

Stephanie was not the only interviewee telling me about the use of wit and ironic responses to take the edge off what was generally seen as sexist acts explicitly expressing male domination within the intimate domain. For instance, Paige (late 20s) discussed how her friend responded to men sending unsolicited DPs by suggesting, for example, that they should hoover their carpet, and Gail (early 20s) shared how she had responded to an unsolicited DP by sending a picture of a sausage slicer in return. However, the most common act of resistance involved the women discussing experiences of receiving such images in a humorous manner with primarily female friends, an activity described by Bella (early 20s) as ‘commiseration':

I would definitely [share the story] with my friend [giggles], just saying 'I just received a random picture of a guy's dick'. [. . . ] Yeah I know, that's definitely a sharing kind of thing. Yeah I know, and it's kind of like, commiseration.

Like Bella, most of the women interviewed for this study claimed that they would process such uncomfortable experiences by talking about it with their primarily female friends. These acts of communal commiseration almost always involved the use of 
humour as a means to belittle the man behind the unsolicited sending. Sometimes, these conversations also involved showing the unsolicited DPs to their friends, in order to laugh at and critique them together. In sharing unsolicited DPs further with their friends in order to laugh at them together, these acts of mockery also operated as a way to prescribe new meanings to unsolicited DPs by suggesting that, rather than expressing any form of male domination, they are, in fact, a great source of amusement (Hess and Flores, 2018: 1085-1086). As argued by Octavia Calder-Dawe (2015: 96-97), 'sexism depends on recognition to function' and, by outwardly reacting with laughter and irony, the women operated so as to 'block' the accommodation of unsolicited DPs as expressions of male power and control (Langton, 2018: 148-149), thus granting them new meanings that deprive them of their 'power to injure' (Butler, 1997: 15). These humorous conversations can therefore also be interpreted as attempts to regain some level of control and agency in and over their digitally mediated interactions with men that involved their receiving of unsolicited DPs (Handyside and Ringrose, 2017; Hess and Flores, 2018). Still, for some of these women, the feeling of catharsis that such acts of communal commiseration involved was short lived.

Some of the interviewees explained how they felt unease about having laughed at unsolicited DPs and the men who sent them, especially when this had involved showing other women the unsolicited images. Verity (late 20s) was one of those who struggled with this notion of regret:

Verity: $\quad[. .$.$] it's like reverse sexism isn't it? Like, we think it's funny to do it to$ them, um but if, if it was us, it would be, I mean, it would just be like you feeling pissed off. [. . . ]

Rikke: So when you show an image [would] that be of your - would that be of the guy you're currently seeing or?

Verity: $\quad$ No. It'd be like, something I didn't want.

According to Verity, she and her friends' showing each other the unsolicited DPs that they had received outside of their intimate and/or sexual relations was 'such a bad thing to do', because it was a form of 'reverse sexism'. To her, any act of further sharing without the explicit consent of a person in the image was an act of sexism, regardless of how the DP had been obtained in the first place. This perception was also reflected in my interview with Isabel (early 20s). At one point in our interview, Isabel was telling me about how her friend had discussed and shown her an unsolicited sexual image - she did not specify whether this was a DP or not - that she had received from a man that Isabel had been 'going out with' - a conversation that Isabel described as 'hilarious'. Suddenly, Isabel stopped in her tracks and exclaimed, 'Um, there you go, isn't that funny: I was so scared of non-consensual sharing [of my private sexual images] and then I participate in non-consensual sharing'. Like Verity (late 20s), Isabel did not distinguish between the further sharing of private sexual images that were obtained consensually, and the further sharing of such images that were received due to unsolicited sending. Owing to this, Isabel derived less pleasure from her act of communal commiseration - at least in retrospect - because she felt guilt about having put this man through the experience of nonconsensual sharing that she herself was so much dreading. 


\section{'Just something to laugh at': understanding online sexism}

I can only speculate as to why it was that some of the women in this study were so reluctant to distinguish between acts of further sharing of private sexual images that were obtained with the consent of the receiver, from the further sharing of those images that had been obtained without the consent of the receiver. Still, I would like to propose that this is yet another illustration of how an inherently individualised postfeminist discursive framework informed the ways that these women understood their experiences of receiving unsolicited DPs, including those experiences that involve their further sharing of unsolicited DPs as a means of communal commiseration, and as a form of humorous anti-sexist resistance. This is so, because this framework does not provide the necessary discursive toolkit for making sense of the broader social structures with regard to gender and sexuality that informs the meanings that unsolicited DPs and, relatedly, acts of communal commiseration take on. For example, in Verity's account earlier, we can see how she made sense of any act of further sharing as sexism, regardless of whether the receiver had wanted the DP or not, and regardless of the gendered elements informing how these images are made sense of in the first place. In doing so, she was operating with the understanding that the sexist nature of such acts is the direct result simply of the individual speaker's intentions to humiliate as they share privately created imagery depicting any form of sexual (self-) representation. With sexism thought of as such, there was, for example, little that distinguished her acts of showing unsolicited DPs to her friends, from those of men who purposefully shared women's private sexual images without their consent to do so, an act that is colloquially (and problematically) known as 'revenge porn' (Henry and Powell, 2016: 400-401; McGlynn et al., 2017: 38). This decontextualised and individualised perception of such acts of communal commiseration was also reflected in my interview with Isabel (early 20s) who, as we have just seen, compared her and friend's act of further distributing an unsolicited private sexual image with the act of further non-consensual sharing of solicited private sexual images that she herself was so worried about.

The individualised understandings of sexism in relation to acts of further sharing as expressed by Isabel and Verity (late 20s), did not account for the social nature of communication or, indeed, of sexism. That is, they did not account for the fact that the meaning of every communicative act, sexist or otherwise, is created in use and according to the predominant conventions within the given context of speech, meaning that these guide how we make sense of such sexual imagery and thus what these images do (Langton, 1993). It is precisely these conventions that make it possible for women's solicited private sexual images - when further distributed against their will and in public - to operate as 'revenge porn', while men's unsolicited DPs are more likely to harm those that receive them, than those depicted in them (Salter, 2016). Arguably, this is the case because what we can do with private sexual images, and who can do what with them, is enabled by the gendered conventions within the socio-technical context in which they occur, meaning that these guide the way in which they are understood by their audience (Amundsen, 2019). Moreover, because these conventions are not gender neutral, but informed by differential perceptions of the male and female gender, they affect women and men differently. My interviewees' lack of a more holistic, social approach to both 
communal commiseration and unsolicited DPs is hence problematic, because it leads to a limited view of the gendered forces and structures that inform and enable communal commiseration to work as counter speech and/or 'reverse sexism', and unsolicited DPs to operate as articulations of online sexism. As such, it also makes it difficult to distinguish from each other the meanings that these acts take on.

Here, I would also like to express my scepticism with regard to the effectiveness of women's use of humour as a means to push back against expressions of sexism online. That is, while such acts of resistance through the application of wit and irony are highly positive in their being moves to challenge expressions of sexism online, I am reluctant to think of these as potential game changers with regard to how especially men's unsolicited DPs are read and understood. Following Calder-Dawe (2015: 100), I am concerned that such relatively small-scale and light-hearted acts of resistance might work so as to secure an uptake of unsolicited DPs as 'not a real problem' (italics in original) and, as such, to allow for the further reproduction of the inherently sexist perceptions that such acts are grounded in Franklin (2015: 30). While these acts might successfully work - at least in part - as a means to ascribe unsolicited DPs new and humorous meanings, they also operate so as to frame them precisely as something that is fun and hence not to be taken too seriously. That is, when presenting such hurtful and disturbing acts as a laughing matter, the women were also operating so as to portray unsolicited DPs as not a proper issue, but as 'just something to laugh at' (Verity, late 20s). Such practices, hence, also came to be further normalised as one of the more annoying, but inevitable, gripes that women have to get used to if they want to go online, especially if their online activities include dating. Nevertheless, this does not need to be case and, in the concluding section of this article, I will suggest that our working so as to situate these acts in relation to the socio-technical contexts in which they occur, is one crucial step towards challenging its prevalence.

\section{Conclusion}

In texts written in 2011, 2014 and 2015, respectively, Sara Ahmed (2015) and Gill (2011, 2014) express their concerns about how the term sexism appears to have disappeared from academic and everyday discourse, with Ahmed (2015) arguing that 'too often, sexism is identified as either in the past tense [. . .] or as elsewhere' (p. 5). They also state that, as people become increasingly reluctant to make use of the term sexism as a means to describe the gendered injustices inherent in certain events and experiences, they are effectively deprived of the opportunities that this term provides for turning these into objects of inquiry (Ahmed, 2015: 5). That is to say, while people might still recognise differential treatment as based on gender as problematic, they lack the necessary 'critical vocabulary' for pinpointing what, precisely, is wrong with these issues in the first place (Gill, 2014: 522). Owing to this, Ahmed (2015) and Gill (2011: 68) call on feminists to bring the term 'sexism' back into our critical terminological frameworks and, in doing so, put systemic gender based discrimination back onto the political agenda.

Today, we might safely proclaim that Ahmed and Gill's call for the return of the term 'sexism' has been heard. Since the publication of their texts on sexism as cited earlier, seismic social and political changes - like the 2016 US presidential election and the 
women's marches that followed it, as well as the global rise of the \#MeToo movement - have brought the term 'sexism' back in vogue in social as well as in political and academic discourse. Nevertheless, while the return of this term to contemporary debate certainly appears as a cause for optimism and a move in the right direction, there is also cause for some careful deliberation about what this reintegration of the term 'sexism' into our critical vocabularies might mean. The ability of sexism to work as a means to describe, recognise and call to attention gender based discrimination, is not inherent in the word itself, but contingent on the meanings that this term gains as it expressed and articulated. In order to assess the operations of the term in the current political climate, and its potential as a means to call out the structural foundations on which gender based discrimination is based, it is hence important to not only consider the frequency with which it is used, but also to look more closely at the meaning that this term gains through use. In order to contribute to this further exploration of how people use the term 'sexism' and what this use might tell us about how people understand it, this article has applied women's accounts of receiving unsolicited DPs as a case study.

According to the traditional, dictionary definition, sexism is a term that refers 'the belief that the members of one sex are less intelligent, able, skilful, and so on than the members of the other sex, especially that women are less able than men' (Cambridge Dictionary, 2017). Understood as such, sexism is also a concept that is part of a wider system (Ahmed, 2015: 9). In line with this understanding of sexism, the women interviewed for this study perceived unsolicited DPs as sexist acts grounded in discriminatory perceptions of (especially female) gender and sexuality, primarily because they were seen as acts grounded in assumptions about male sexual entitlement and a related lack of respect for women's right to self-govern and exercise sexual control (Hayes and Dragiewicz, 2018). As follows, they also operated with an understanding of consent as something that is inherently linked to their individual choice and autonomy. Still, unlike this conception of sexism, some of these women were reluctant to view it as part of an overarching system. Essentially, they operated with a perception of unsolicited DPs that was detached from the broader structures that shape, form and enable such acts from the outset. While none of the interviewees shied away from using sexism and related terms in order to explain their experiences, they lacked the necessary critical discursive framework to comprehend how and why certain communicative acts involving particular forms of sexual imagery can come to operate as sexism, while other similar communicative acts including the same or remarkably similar material, and occurring in almost identical contexts - like their own acts of communal commiseration - are less likely to do so.

In this article, I have stated that my interviewees' reluctance to situate their accounts of unsolicited DPs as a form of online sexism in relation to the broader context in which they occur is a consequence of their reliance on a postfeminist discursive framework, foregrounding notions of individual agency, free choice and female empowerment (Gill, 2007). I have shown how the 'grammar of individualism' that underpins this discursive framework leads those who adopt it to develop particularly individualised and decontextualised understandings of unsolicited DPs as sexism, meaning that the predominant gendered conventions operating in their contexts of circulation and enabling the sexist meanings that they take on, are obscured from view (Gill, 2007: 153). When operating 
with an approach to sexism such as this, concepts like sexism become 'floating [signifiers], with few, if any implications for action' (Gill and Favaro, 2018: 61). However, if the broader aim in calling out sexist DP behaviour is to prevent it from happening in the future, this kind of omission - whether in women's individual or communal efforts or in academic work on this issue - is problematic, primarily because it means that a significant enabling element involved in this issue is excepted from our critical attention and consideration. For future research in this field, closer examination of the predominant gendered conventions operating in the socio-technical context, in which unsolicited DPs circulate, would hence provide a useful contribution to our developing an improved understanding of this practice and the meanings that it takes on. Such research could, for example, consist of a combination of media and communication with science and technology studies - hence, opening up for a close examination of the material and social elements that come together in creating the socio-technical context that enables both the distribution of unsolicited DPs and their harmful meanings. Social conventions do not simply inform the humans who use technology, but also the people who design, create and maintain it, meaning that these shape and form the technology used for these purposes too (Massanari, 2015; Wajcman, 2004). Closer explorations of the technologies used for unsolicited DP practices and of those that provide them, combined with in-depth qualitative explorations of men's motivations and expectations as they create and send DPs to women - consensually or non consensually - would therefore provide a much-needed further examination of the various ways that gendered conventions inform unsolicited DP practices at the various stages of the communicative practice. In shedding light on the underlying forces that feed off and into men's motivations and expectations as they engage in unsolicited DP practices, this research would go beyond the limited existing research concerned with this particular socio-technical phenomenon (e.g. Oswald et al., 2019).

\section{Acknowledgements}

Many thanks to the women who participated in this research. The author would also like to express her gratitude to Dr Ella McPherson for her guidance and advice as the author conducted the research and developed the insights on which she draws in this article. The author is grateful to the two anonymous reviewers for their insightful and encouraging feedback.

\section{Funding}

The author(s) received no financial support for the research, authorship, and/or publication of this article.

\section{ORCID iD}

Rikke Amundsen (iD https://orcid.org/0000-0002-4841-6684

\section{Notes}

1. A recent survey by YouGov found that 4 in 10 British women aged 18-36 have received an unsolicited DP (Smith, 2018). Only 5\% of the male survey respondents within the same age group claimed to have sent one. 
2. Thank you to the anonymous reviewer who suggested I include this note about the significance of age in DP research.

3. See for example, Sarah Handyside and Jessica Ringrose (2017), Aaron Hess and Carlos Flores (2018), Ringrose and Lawrence (2018), Frances Shaw (2016) and Laura Vitis and Fairleigh Gilmour (2017).

4. For further research exploring the similarities between unsolicited private sexual images and offline flashing, see Rebecca M. Hayes and Dragiewicz (2018), Ringrose and Lawrence (2018), Michael Salter (2016) and Laura Thompson (2016).

5. This finding is similar to that of Salter (2016), whose female research participants described men's unsolicited sharing of private sexual images as an inevitable practice.

\section{References}

Ahmed S (2015) Introduction: sexism - a problem with a name. New Formations: A Journal of Culture/Theory/Politics 86: 5-13.

Amundsen R (2019) 'Kind of like making porn of yourself': understanding sexting through pornography. Feminist Media Studies 19(4): 479-494.

Banet-Weiser S, Gill R and Rottenberg C (2019) Postfeminism, popular feminism and neoliberal feminism? Sarah Banet-Weiser, Rosalind Gill and Catherine Rottenberg in conversation. Feminist Theory 21(1): 3-24.

Brah A and Phoenix A (2013) Ain't I a woman? Revisiting intersectionality. Journal of International Women's Studies 5(3): 75-86.

Braun V and Clarke V (2006) Using thematic analysis in psychology. Qualitative Research in Psychology 3(2): 77-101.

Brown W (2003) Neo-liberalism and the end of liberal democracy. Theory \& Event 7(1). Available at: http://lchc.ucsd.edu/cogn_150/Readings/brown.pdf

Burkett M (2015) Sex(t) talk: a qualitative analysis of young adults' negotiations of the pleasures and perils of sexting. Sexuality \& Culture 19(4): 835-863.

Butler J (1990) Gender Trouble: Feminism and the Subversion of Identity. London; New York: Routledge.

Butler J (1997) Excitable Speech: A Politics of the Performative. London; New York: Routledge.

Calder-Dawe O (2015) The choreography of everyday sexism: reworking sexism in interaction. New Formations: A Journal of Culture/Theory/Politics 86: 89-105.

Cambridge Dictionary (2017) Sexism. Cambridge University Press. Available at: https://dictionary.cambridge.org/dictionary/english/sexism (accessed 11 December 2017).

Franklin S (2015) Sexism as a means of reproduction: some reflections on the politics of academic practice. New Formations: A Journal of Culture/Theory/Politics 86: 14-33.

Gill R (2007) Postfeminist media culture: elements of a sensibility. European Journal of Cultural Studies 10(2): 147-166.

Gill R (2011) Sexism reloaded, or, it's time to get angry again! Feminist Media Studies 11(1): $61-71$.

Gill R (2014) Unspeakable inequalities: post feminism, entrepreneurial subjectivity, and the repudiation of sexism among cultural workers. Social Politics: International Studies in Gender, State \& Society 21(4): 509-528.

Gill R (2017) The affective, cultural and psychic life of postfeminism: a postfeminist sensibility 10 years on. European Journal of Cultural Studies 20(6): 606-626.

Gill R and Favaro L (2018) Feminism rebranded: women's magazines and the return of the F-word. Dígitos 4: 37-65.

Handyside S and Ringrose J (2017) Snapchat memory and youth digital sexual cultures: mediated temporality, duration and affect. Journal of Gender Studies 26(3): 347-360. 
Hayes RM and Dragiewicz M (2018) Unsolicited dick pics: erotica, exhibitionism or entitlement? Women's Studies International Forum 71: 114-120.

Henry N and Powell A (2016) Sexual violence in the digital age: the scope and limits of criminal law. Social \& Legal Studies 25(4): 397-418.

Hess A and Flores C (2018) Simply more than swiping left: a critical analysis of toxic masculine performances on Tinder Nightmares. New Media \& Society 20(3): 1085-1102.

Kaiser K (2009) Protecting respondent confidentiality in qualitative research. Qualitative Health Research 19(11): 1632-1641.

Langton R (1993) Speech acts and unspeakable acts. Philosophy \& Public Affairs 22(4): 293-330.

Langton R (2018) Blocking as counter-speech. In: Harris DW, Fogal D and Moss M (eds) New Work on Speech Acts. New York: Oxford University Press, pp. 145-164.

McGlynn C, Rackley E and Houghton R (2017) Beyond 'revenge porn': the continuum of imagebased sexual abuse. Feminist Legal Studies 25(1): 25-46.

McRobbie A (2004) Post-feminism and popular culture. Feminist Media Studies 4(3): 255-264.

McRobbie A (2009) The Aftermath of Feminism: Gender, Culture, and Social Change. London: SAGE.

Mandau MBH (2020) 'Directly in your face': a qualitative study on the sending and receiving of unsolicited 'dick pics' among young adults. Sexuality \& Culture 24: 72-93.

Massanari A (2015) \#Gamergate and The Fappening: how Reddit's algorithm, governance, and culture support toxic technocultures. New Media \& Society 19: 329-346.

O’Neill R (2018) Seduction: Men, Masculinity and Mediated Intimacy. Medford, MA: Polity Press.

Oswald F, Lopes A, Skoda K, et al. (2019) I'll show you mine so you'll show me yours: motivations and personality variables in photographic exhibitionism. The Journal of Sex Research 1. DOI: $10.1080 / 00224499.2019 .1639036$.

Paasonen S, Light B and Jarrett K (2019) The dick pic: harassment, curation, and desire. Social Media + Society 5(2): 826126.

Ricciardelli R and Adorjan M (2019) 'If a girl's photo gets sent around, that's a way bigger deal than if a guy's photo gets sent around': gender, sexting, and the teenage years. Journal of Gender Studies 28(5): 563-577.

Ringrose J and Harvey L (2015) Boobs, back-off, six packs and bits: mediated body parts, gendered reward, and sexual shame in teens' sexting images. Continuum 29(2): 205-217.

Ringrose J and Lawrence E (2018) Remixing misandry, manspreading, and dick pics: networked feminist humour on Tumblr. Feminist Media Studies 18(4): 686-704.

Rose N (1996) Inventing Our Selves: Psychology, Power, and Personhood. Cambridge: Cambridge University Press.

Roulston K (2010) Reflective Interviewing: A Guide to Theory and Practice. London: SAGE.

Salter M (2016) Privates in the online public: sex (ting) and reputation on social media. New Media \& Society 18(11): 2723-2739.

Setty E (2018) Young men and sexting: it's not always easy being a teenage boy in youth digital sexual culture. Discover Society, 1 August. Available at: https://discoversociety. org/2018/08/01/young-men-and-sexting-its-not-always-easy-being-a-teenage-boy-in-youthdigital-sexual-culture/ (accessed 6 August 2018).

Setty E (2020) 'Confident' and 'hot' or 'desperate' and 'cowardly'? Meanings of young men's sexting practices in youth sexting culture. Journal of Youth Studies 23(5): 561-577. DOI: 10.1080/13676261.2019.1635681.

Smith M (2018) Four in ten female millennials have been sent an unsolicited penis photo. Available at: https:/yougov.co.uk/topics/politics/articles-reports/2018/02/16/four-ten-female-millennials-been-sent-dick-pic (accessed 5 March 2019). 
Shaw F (2016) "Bitch I said hi": the bye felipe campaign and discursive activism in mobile dating apps. Social Media + Society 2(4): 1-10.

Thompson L (2016) \#DickPics are no joke: cyber-flashing, misogyny and online dating. The Conversation, 3 February. Available at: http://theconversation.com/dickpics-are-no-jokecyber-flashing-misogyny-and-online-dating-53843 (accessed 21 August 2018).

Vitis L and Gilmour F (2017) Dick pics on blast: a woman's resistance to online sexual harassment using humour, art and Instagram. Crime, Media, Culture: An International Journal 13(3): $335-355$.

Wajcman J (2004) TechnoFeminism. Cambridge: Polity Press.

\section{Author biography}

Rikke Amundsen is a Teaching Associate in Sociology at the University of Cambridge, UK. 